\title{
Impacts of Improved Supplemental Irrigation on Farm Income, Productive Efficiency and Risk Management in Dry Areas
}

\author{
Tamer El-Shater, Yigezu A. Yigezu*, Kamil Shideed, Aden Aw-Hassan \\ International Center for Agricultural Research in the Dry Areas (ICARDA), Amman, Jordan \\ Email: *y.yigezu@cgiar.org
}

How to cite this paper: El-Shater, T., Yigezu, Y.A., Shideed, K. and Aw-Hassan, A. (2017) Impacts of Improved Supplemental Irrigation on Farm Income, Productive Efficiency and Risk Management in Dry Areas. Journal of Water Resource and Protection, 9, 1709-1720.

https://doi.org/10.4236/jwarp.2017.913106

Received: October 25, 2017

Accepted: December 26, 2017

Published: December 29, 2017

Copyright (c) 2017 by authors and Scientific Research Publishing Inc. This work is licensed under the Creative Commons Attribution International License (CC BY 4.0).

http://creativecommons.org/licenses/by/4.0/

\begin{abstract}
This paper provides empirical evidence that improved supplemental irrigation (ISI) can be justified on both environmental and economic grounds. Results of a stochastic frontier model which explicitly and simultaneously accounts for technical inefficiency and production risk applied to data collected from 513 wheat farms in the rainfed areas of Syria show that the typical adopter farmer obtained yield and productive efficiency gains of $6 \%$ and $7 \%$ respectively. A stochastic dominance criterion also showed that the adopter farmers got $10 \%$ and $13 \%$ reductions in risk of obtaining yield levels below 4 tons/ha and 3 tons/ha respectively. Given its adoption level of $22.3 \%$ in 2010, ISI led to the production of 52 thousand metric tons (6\%), more wheat and conservation of 120 million cubic meters of water (10\%). ISI has the potential to reduce total irrigation water use by upto $45 \%$ and for further increases in yield if accompanied with sprinklers and other improved agronomic practices, thereby enhancing food security and environmental sustainability in the country. An important policy implication of these findings is that wider dissemination of ISI along with other complementary agronomic practices in postwar Syria could be a viable option to be considered by national and international efforts for the restoration and rehabilitation of agriculture in the country.
\end{abstract}

\section{Keywords}

Supplemental Irrigation, Wheat Yield, Technical Inefficiency, Production Risk, Stochastic Frontier Production Function, Stochastic Dominance

\section{Introduction}

Agriculture in the dry areas is exposed to a variety of risks which occur with high 
frequency where the stochastic nature of agricultural production is the major source of risk [1]. The factors which cause variability in agricultural production include weather, pests and diseases. Risks in agricultural production are confounded by market fluctuations which are more significant in developing countries due to market imperfections, poor information, infrastructure and communication networks.

Yield variability is often explained by external factors such as weather, pests, diseases and input and output prices that are outside the control of farmers. However, factors, such as variability in agronomic conditions including levels of inputs applied, which are under the control of farmers, also play important roles [2]-[7].

Farmers in developing countries are generally risk-averse [8] [9]. This is mainly due to the absence of crop insurance and government support that buffer agricultural risk and provide the needed cushion at times of difficulty. Moreover, agricultural production in the developing world is highly associated with food security and hence the wellbeing of the family. Focusing on the developing world, poor farmers are more averse to risk and more likely to be reluctant to adopt technologies that increase risk [10]. The same study argued that risk-averse farmers are likely to consider both the level of income and risk simultaneously and to reject a technology that they consider too risky.

Water scarcity is a critical constraint to agriculture in dry areas. This problem is likely to become more severe because of population growth, climate change and deterioration of water quality. Characterized by low average amounts and high variability of rainfall, agricultural production in the dry areas carries substantial risk. In its effort to help farmers in the dry areas, the International Center for Agricultural Research in the Dry Areas (ICARDA) along with the national agricultural research institutions of many countries in the Middle Eastern and North African region has introduced the practice of improved supplemental irrigation (ISI) in predominantly rainfed areas. Improved supplemental irrigation (ISI) is the addition of small amounts of water to essentially rain-fed crops during times when rainfall fails to provide sufficient moisture for normal plant growth, in order to improve and stabilize yields [11] [12]. In ISI, water is applied to rainfed crops which would normally produce some yield without irrigation. ISI is only applied when rainfall fails to provide essential moisture for improved and stable production, and the amount and timing are scheduled to ensure that a minimum amount of water is available during critical stages of crop growth [11].

The components of the new improved supplemental irrigation technology focused on irrigation scheduling: when to irrigate, how to irrigate, and how much water to use [13]. The improved supplemental irrigation practice often recommended with a technology packages involving improved crop varieties (mainly wheat) and organic fertilizers. The introduction of ISI does not only help in stabilizing yield levels, but also in increasing the average yield in countries where farmers use the traditional supplemental irrigation (TSI) where irrigation water 
application rates are well above the marginal product and even yield maximizing levels. [14] found that ISI leads to maximum yield gains if coupled with sprinkler technologies.

Using data from 513 Syrian wheat farmers and the stochastic frontier production function, this paper argues and tries to provide empirical evidence that the adoption of ISI reduces the risks of yield variability and the associated variability in technical efficiency. The findings of this study are expected to be useful to researchers, policy makers, development organizations and extension personnel in their effort to help farmers in the dry areas cope with water scarcity induced by climate change.

\section{Description of the Study Area}

Syria is highly vulnerable to climate change. Located in the western part of the Mediterranean basin, Syria has a surface area of $185,518 \mathrm{~km}^{2}$ and 32.2 percent is of this area is cultivable. Total irrigated land has more than doubled in 20 years between 1985 and 2005 [15]. The demand for irrigation water has also increased steadily over the decades, almost doubling since 1985 [16]. Excessive pumping is leading to rapid depletion of the ground water resource. Current water deficit in Syria ranges between 2.85 and 4.70 billion $\mathrm{m}^{3} /$ year [17]. As a result, groundwater levels in many parts of the country have dropped between 2 - 6 meters and in some others even by more than 6 meters per year between 1993 and 2000 [18].

Wheat is the most important food grain grown in Syria. It is a crop of strategic political importance due to its high potential to enhance food security. In 2011, wheat was cultivated on nearly 1.8 million hectares, with a total production of 4.9 million metric tons [19], only 45 percent of the land area under wheat cultivation was irrigated, yet this irrigated area accounted for 72 percent of wheat production. The disparity between irrigated land area under wheat cultivation and its contribution to production and productivity indicates the importance of land and water resources management for wheat production, especially in the rainfed wheat area. The typical irrigation method at the field level in Syria is a surface gravity system [20]. Traditional surface canal irrigation using open canal networks accounts for over $80 \%$ of total irrigated lands in Syria.

Water use efficiency (WUE), which is the ratio of the amount of water actually utilized by the crop to the total water pumped, for irrigated agriculture in Syria stands at about $40 \%-60 \%$ [17] [20]. This is due to inefficient management of water resources, especially at the farm level, where traditional irrigation methods are practiced. In this area, transpiration and seepage alone account for $10 \%$ $60 \%$ of total water loss due to traditional surface canal irrigation [21]. Traditional surface canal irrigation methods also lead to over-irrigation especially in the absence of adequate land leveling. In most cases, the design of the traditional furrow irrigation system in Syria is not optimal [20]. Moreover, fields are not well drained, furrows are not well maintained and land leveling is not done regularly which results in some parts of the field receiving excessive water. 
Prior to the introduction of the improved supplemental irrigation (ISI) by ICARDA and the Ministry of Agriculture (MoA), all Syrian wheat growers used irrigation techniques that resulted in high water use per unit area. Thus current adoption of improved supplemental irrigation (ISI) technology by $22.3 \%$ of Syrian wheat farmers has resulted in water savings and sustained wheat farming systems, generating huge environmental benefits. Applying supplemental irrigation in one or two well-timed applications at heading, anthesis, or milk stage can lead to increased and stabilized yield. To avoid confusion, we make distinction in this paper between improved supplemental irrigation (ISI), in which the recommended water application rates are used and traditional supplemental irrigation (TSI) where farmers use excessive irrigation over the recommended levels $^{1}$.

\section{Material and Methods}

\subsection{Data}

Owing to their relatively high share in total rainfed wheat land in the country and also the tremendous scope for ISI, zones 1 and 2 of Syria have been chosen for this study. From among the total of 14 governorates in the country, 12 have areas which fall in zones 1 and 2 out of which, the top three wheat producing governorates (Aleppo, Deraa and Al-Hassakeh) were chosen for this study. These three governorates account for about $66 \%$ of total wheat land and $61 \%$ of total wheat production in Syria.

Using power analysis, the minimum sample size needed to ensure $95 \%$ confidence level for estimating the total number of ISI adopters was calculated to be 513. A stratified sampling procedure was then used to proportionally distribute the sample among the two zones where 241 and 272 households were drawn from Zones 1and 2 respectively. The distribution of these households into the two zones and 26 randomly drawn villages across the three governorates are provided in Table 1 below.

\subsection{Methodology}

The stochastic frontier production function approach has been widely applied to analyze technical efficiency in production [22] [23] [24] [25]. By extending the application of the stochastic frontier production function approach, [26] propose a new measure of input-specific technical efficiency (TE) in production. They also apply the new method to study the technical inefficiency of irrigation water among out-of-season vegetable growers in Crete, Greek. [27] also applied the method to study the technical inefficiency of irrigation water in citrus producing farms in Nabeul, Tunisia. Both studies find low (47.2\% and 53\%) mean

${ }^{1}$ Scheduling of SI is determined for each year using the water balance method. For instance, in zones 1 and 2 of Syria, which are the study areas for this research, optimum yields were obtained with ISI of 600 to $1800 \mathrm{~m}^{3} / \mathrm{ha}$ [16]. Hence, in this analysis, we used the higher end $\left(1800 \mathrm{~m}^{3}\right)$ as the upper limit for the amount of water applied under ISI. 
Table 1. Number of villages and households selected randomly by zone and governorate.

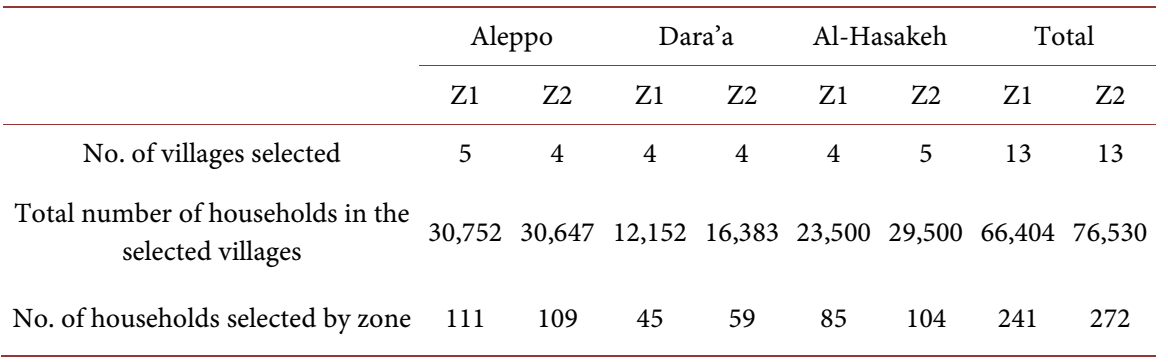

irrigation water use technical efficiency with very high variability ranging between $23.9 \%-98.63 \%$ and $1.6 \%-98.87 \%$, respectively. The low estimated mean irrigation water efficiency results show that using the observed values of other inputs and 53\% and $47 \%$ less irrigation water respectively, the observed quantities of outputs could be produced. The typical stochastic frontier production function can be specified as:

$$
\ln \left(y_{i}\right)=f\left(x_{i}, \beta\right)+v_{i}-u_{i}
$$

where $y_{i}$ is a scalar output of production unit $I ; x_{i}$ is a vector of $N$ inputs used by producer $I ; f\left(x_{i}, \beta\right)$ is the deterministic part of the production frontier; $\beta$ is a vector of technology parameters to be estimated; and $v_{i}$ and $u_{i}$ are noise and inefficiency components which can take a number of forms, depending on specific assumptions. The specification given by (Equation (1)) is consistent with the typical Just-Pope framework [28] under the following assumption:

$$
\begin{gathered}
u_{i}=0 \\
v_{i} \sim N\left(0, \sigma_{v i}^{2}\right) \\
\sigma_{v i}^{2}=\exp \left(z_{i} \gamma\right)
\end{gathered}
$$

where $z_{i}$ is an input vector which may or may not equal $x_{i}$ and $\gamma$ is a vector of parameters. So the Just-Pope framework takes the form:

$$
y=f\left(x_{i}, \beta\right)+h\left(z_{i}, \gamma\right)
$$

where the function $h\left(z_{i}, \gamma\right)$ represents the output risk function. More recent advances in efficiency analysis showed that stochastic production frontier models can include the technical inefficiency and production risk simultaneously [29] [30]. This approach allows for heteroscedasticity in the noise component to investigate risk effects while also allowing for heterogeneity in the mean of the inefficiency term during analysis of inefficiency effects. The model requires the estimation of Equation (1) with the following assumptions:

$$
\begin{gathered}
v_{i} \sim N\left(0, \sigma_{v i}^{2}\right) \\
\sigma_{v i}^{2}=\exp \left(z_{i} \gamma\right) \\
u_{i} \sim N^{+}\left(\bar{u}_{i}, \sigma_{u i}^{2}\right)
\end{gathered}
$$




$$
\bar{u}_{i}=\omega_{i} \alpha
$$

Following the conventional specification in the stochastic production frontier model, the random error $v_{i}$ follows a normal distribution with zero mean and variance $\sigma_{v i}^{2}$, and the inefficiency term $u_{i}$ follows a truncated-normal distribution with mean $\bar{u}_{i}$ and variance $\sigma_{u i}^{2}$. To capture the heterogeneity of the efficiency and risk terms, the mean efficiency and risk functions are determined by exogenous factors. The vector $\omega_{i}$ denotes exogenous variables that have influence on the mean value of production inefficiency.

The risk function is assumed to have an exponential functional form with the vector of the exogenous factors $z_{i}$ as explanatory variables [28] [29]. The notation $\alpha$ is a vector of parameters associated with the mean of the production inefficiency while the notation $\gamma$ is the vector of parameters associated with the production risk. The consistent estimators of Equation (3) can be obtained by using the maximum likelihood estimation method on the following log- likelihood function [28] [31].

$$
\begin{aligned}
\ln L= & \text { constant }-\frac{1}{2} \sum_{i} \ln \left[\exp \left(z_{i} \gamma\right)+\exp \left(k_{i} l\right)\right] \\
& +\sum_{i} \ln \phi\left(\frac{h_{i} a}{\sigma_{i} \lambda_{i}}-\frac{\varepsilon_{i} \lambda_{i}}{\sigma_{i}}\right)-\frac{1}{2} \sum_{i} \frac{\left(\varepsilon_{i}+h_{i} \alpha\right)^{2}}{\sigma_{i}^{2}}
\end{aligned}
$$

where $\sigma_{i}^{2}=\sigma_{v i}^{2}+\sigma_{u i}^{2} ; \quad \varepsilon_{i}=y_{i}-x_{i} \beta ; \quad \lambda_{i}=\left[\exp \left(k_{i} l-z_{i} r\right)\right]^{0.5}$

Following [29] [30], we estimate the stochastic production frontier models which included the technical inefficiency and production risk simultaneously for the wheat farmers in the study area. The list and description of variables included in the model are provided in Table 2. The measure of output oriented technical efficiency ( $T E$ ) for the $i^{\text {th }}$ farmer (i.e., the ratio of the outputs with and without inherent inefficiencies) can then be computed as:

$$
\begin{gathered}
T E_{i}=\frac{f\left(X_{i j}, \beta_{i j}, v_{i}, u_{i}\right)}{f\left(X_{i j}, \beta_{i j}, v_{i}\right)} \\
T E=\exp \left(-u_{i t}\right)=\exp \left(-z_{i t} \delta-w_{i t}\right)
\end{gathered}
$$

where, $0 \leq T E \leq 1$ and the closer the $T E$ score to 1 , the higher the efficiency. In this specification, the parameters, $\beta, \sigma, \sigma_{u}$, and $\delta$ have been estimated simultaneously using the maximum likelihood method. Thus, the log likelihood ratio (LR), which has a chi-square distribution, is used to test the significance of parameter estimates.

\section{Results}

Model results show that wheat area, application rates of Nitrogen and Phosphorus fertilizers, seed rate and quantity of Labor used had positive and significant effect on yield-showing that at their current average application levels, an increase in any of the five inputs leads to yield increase (Table 3). Yield responses to seeds, phosphorus fertilizers, labor, and wheat area respectively are $0.13,0.08,0.07$ and 0.03 . 
Table 2. Explanatory variables included in the model.

\begin{tabular}{ccccc}
\hline \multirow{2}{*}{ Variables } & \multicolumn{3}{c}{ Average value } \\
\cline { 2 - 5 } & Unit & ISI & TSI & FI \\
\hline Quantity of irrigation water & $\mathrm{m}^{3} / \mathrm{ha}$ & 1460 & 1615 & 2766.7 \\
Wheat area & $\mathrm{Ha}$ & 3.7 & 2.8 & 3.4 \\
Nitrogen quantity & $\mathrm{kg} / \mathrm{Ha}$ & 132 & 138 & 148 \\
Phosphorus quantity & $\mathrm{kg} / \mathrm{Ha}$ & 49.4 & 84.3 & 62.7 \\
seed quantity & $\mathrm{kg} / \mathrm{Ha}$ & 250 & 260 & 275 \\
Labor & Hour & 32.2 & 38.9 & 57 \\
Farmer age & Year & 51.7 & 53.8 & 52.6 \\
years of schooling & Year & 8 & 6.8 & 3.7 \\
Farm size & Ha & 11.5 & 8.1 & 11 \\
\hline
\end{tabular}

Source: survey data.

The insignificance of the linear irrigation water term should not come by surprise as the descriptive statistics from our sample survey show that the typical farmer is applying about $1110 \mathrm{~m}^{3} / \mathrm{ha}$ in excess of the maximum of the recommended range of $600-1800 \mathrm{~m}^{3} / \mathrm{ha}$. The profit maximizing level of irrigation water is $2032 \mathrm{~m}^{3} /$ ha showing that the typical farmer is producing on the downward slopping part of the total product curve where marginal product of irrigation water is negative.

From the inefficiency model, the negative and significant coefficient on the use of improved supplemental irrigation indicates that improved supplemental irrigation reduce inefficiency-a result that is consistent with the theoretical expectation as improved supplemental irrigation is believed to ensure better utilization of water by plants. The positive and significant coefficient on the soil salinity variable shows that at its current average, an increase in soil salinity would lead to higher inefficiency. The coefficient on the years of schooling is negative and significant. This shows that more farmer education reduces inefficiency, which is consistent with what one can expect.

A closer look at the efficiency figures shows that $11.9 \%$ of the farmers who had used ISI have efficiency levels of between 90 to 100 percent. The corresponding figure for farmers who had used full irrigation (FI) and TSI is 0. Regardless of their irrigation method (surface canal or sprinkler), $77.4 \%$ of farmers who used ISI have efficiency rates of greater than 70 percent, which is much higher than that of those who had used FI and TSI which exhibit irrigation water efficiency levels of $38 \%$ and $52.6 \%$ respectively-a clear indication that using ISI leads to improvements in productive efficiency (Figure 1).

In the risk function, the coefficients on improved supplemental irrigation (ISI), Nitrogen fertilizer and, improved wheat variety are negative and significant showing that they contribute to the reduction of production risk. The negative and significant coefficient on ISI is consistent with the theoretical expectation as yield stability is one of the main benefits of ISI. The stochastic dominance 
Table 3. Estimations of the stochastic frontier production function.

\begin{tabular}{|c|c|c|}
\hline \multicolumn{3}{|l|}{ Deterministic frontier } \\
\hline Inputs/Attributes & Coefficient & Std. err. \\
\hline Quantity of irrigation water $\left(\mathrm{m}^{3} / \mathrm{ha}\right)$ & 0.0074 & 0.0055 \\
\hline Wheat area $(\mathrm{Ha})$ & 0.0277 & $(0.0106)^{* * *}$ \\
\hline $\mathrm{N}(\mathrm{kg} / \mathrm{Ha})$ & 0.1225 & $(0.0139)^{* * *}$ \\
\hline $\mathrm{P}(\mathrm{kg} / \mathrm{Ha})$ & 0.0756 & $(0.0085)^{* * *}$ \\
\hline seed $(\mathrm{kg} / \mathrm{Ha})$ & 0.1344 & $(0.0297)^{\star * *}$ \\
\hline Labor (hour) & 0.0702 & $(0.0166)^{* * *}$ \\
\hline Constant & 6.6405 & $(0.1400)^{* * *}$ \\
\hline \multicolumn{3}{|l|}{ Risk function } \\
\hline Soil salinity $(0=$ Low and $1=$ High $)$ & 0.0934 & $(0.0305)^{* * *}$ \\
\hline Wheat area $(\mathrm{Ha})$ & -0.0003 & 0.0014 \\
\hline $\mathrm{N}(\mathrm{kg} / \mathrm{Ha})$ & -0.0002 & $(0.0001)^{*}$ \\
\hline $\mathrm{P}(\mathrm{kg} / \mathrm{Ha})$ & 0.0019 & 0.0034 \\
\hline Wheat variety $(0=$ Local and $1=$ Improved $)$ & -0.9128 & $(0.4970)^{*}$ \\
\hline Labor (hour) & -0.0004 & 0.0037 \\
\hline Surface Supplemental irrigation $(0=$ No and $1=$ Yes $)$ & 0.0463 & $(0.0261)^{\star}$ \\
\hline Improved supplemental irrigation $(0=$ No and $1=\mathrm{Yes})$ & -0.1378 & $(0.0400)^{* * *}$ \\
\hline Constant & -5.4658 & $(0.4840)^{* * *}$ \\
\hline \multicolumn{3}{|c|}{ Mean function of inefficiency } \\
\hline Farmer age (year) & -0.0007 & 0.0045 \\
\hline years of schooling (year) & -0.0786 & $(0.0155)^{* * *}$ \\
\hline Farm size $(\mathrm{Ha})$ & -0.0030 & 0.0094 \\
\hline Soil salinity $(0=$ Low and $1=$ High $)$ & 0.6098 & $(0.2246)^{* * *}$ \\
\hline Wheat variety $(0,1)$ & -0.0152 & 0.1672 \\
\hline Surface Supplemental irrigation $(0=$ No and $1=$ Yes $)$ & -0.3646 & $(0.1999)^{\star}$ \\
\hline Improved supplemental irrigation $(0=$ No and $1=$ Yes $)$ & -0.9111 & $(0.3573)^{* * *}$ \\
\hline Constant & -2.4218 & $(0.2888)^{* * *}$ \\
\hline Log likelihood & 276.8000 & \\
\hline
\end{tabular}

Dependent Variable: natural logarithm of yield $(\mathrm{kg} / \mathrm{ha}) ;{ }^{* *},{ }^{* *},{ }^{*}$ indicate significance at the $1 \%, 5 \%$, and $10 \%$ levels.

criterion also showed that ISI first degree stochastically dominates TSI and the shift from TSI to ISI led to $10 \%$ and $13 \%$ reductions in the risk of obtaining yield levels below 4 tons/ha and 3 tons/ha respectively (Figure 2).

The negative and significant coefficients on improved wheat varieties (IVs) are also consistent as the drought tolerance characteristics of IVs is expected to reduce yield variability. However, the negative and significant coefficient on $\mathrm{Ni}$ trogen fertilizers is counterintuitive because if the amount of irrigation water 


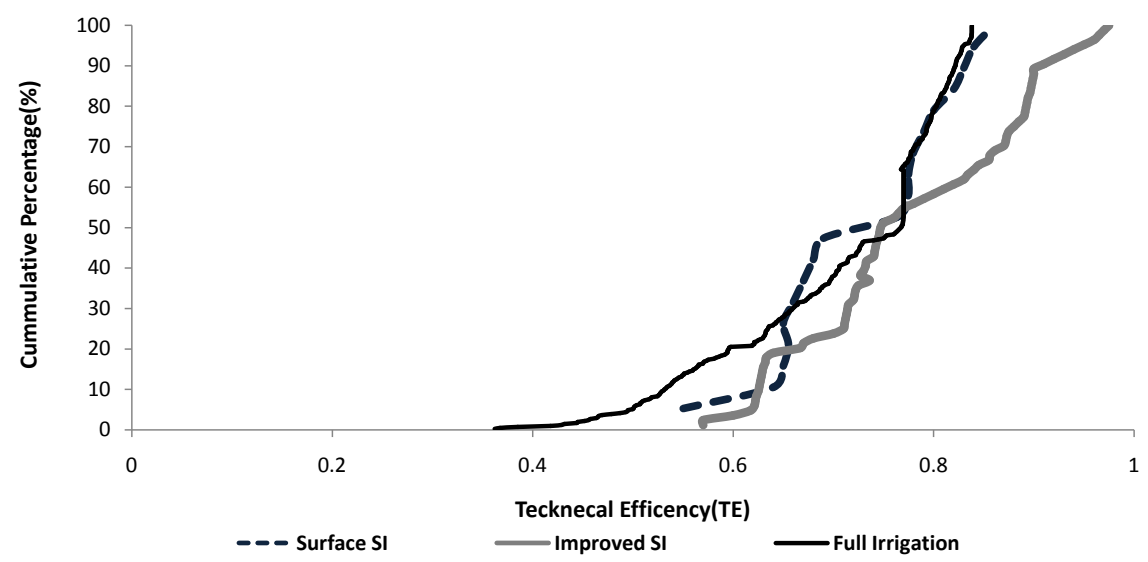

Figure 1. Cumulative distribution of the estimated efficiency by irrigation categories.

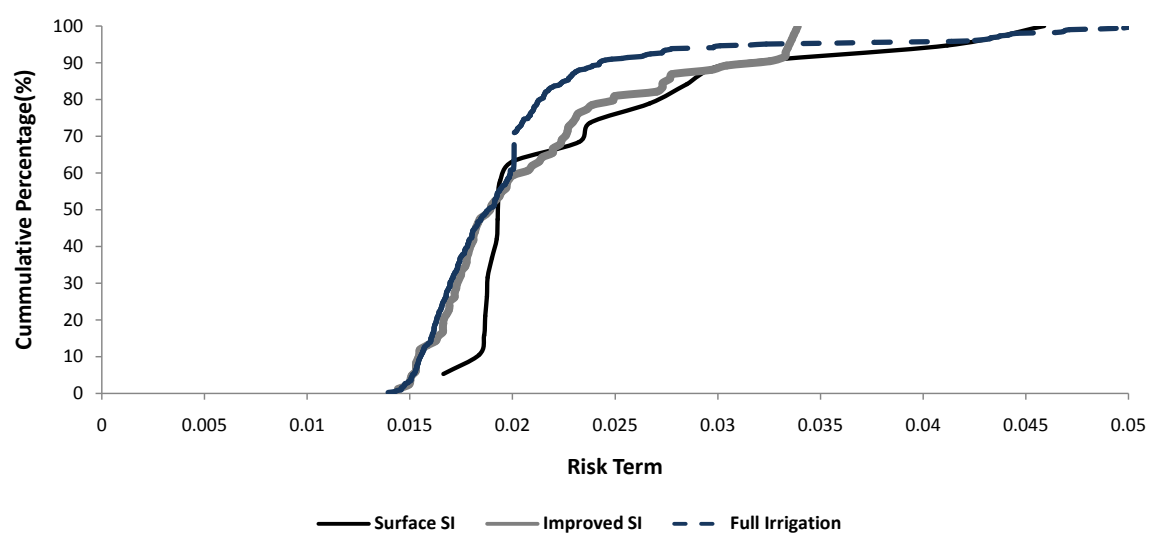

Figure 2. Risk comparisons between irrigation methods using the stochastic dominance criterion.

made available to the crop is very low, fertilizers could possibly have burning effect and hence lead to lower yield levels than what is achievable without fertilizers. These results indicate that risk-averse farmers can use ISI, improved wheat varieties and fertilizers in order to reduce the production risk and hence the revenue variability. Further analysis of the data shows that risk-averse farmers are less likely to adopt supplemental irrigation with surface canal because adoption of SI with surface canal (instead of sprinklers) can increase the variability in production.

\section{Conclusions and Recommendations}

Using a survey of 513 Syrian wheat farms as case study and a stochastic frontier production function model which explicitly and simultaneously accounts for technical inefficiency and production risk, this paper provided empirical evidence that a shift from both flood irrigation (FI) and traditional supplemental irrigation (TSI) to improved supplemental irrigation (ISI) in rainfed agriculture, particularly in the dry areas, increases technical efficiency and reduces production risk and increases yield, thereby contributing to national food security. 
At current average application rate of $1490 \mathrm{~m}^{3} / \mathrm{ha}$, the adopters of ISI are using about $1110 \mathrm{~m}^{3} / \mathrm{ha}(43 \%)$ irrigation water less than those using TSI. Therefore, at its current adoption level of $22.3 \%$, ISI leads to the conservation of about 120 million $\mathrm{m}^{3}$ (10\% of total) irrigation water in the country. This shows that if all farmers in the country were to shift to ISI, it has the potential of cutting the total amount of irrigation water by about $45 \%$. With a negative and significant coefficient in the inefficiency model, the use of improved supplemental irrigation reduces inefficiency-a result that comes without a surprise as improved supplemental irrigation is believed to ensure better utilization of water by plants.

Analysis of estimates from the inefficiency model shows that $11.9 \%$ of the farmers who had used ISI have efficiency levels between 90 and 100 percent. The corresponding figure for farmers who had used FI and TSI is 0. Likewise, regardless of the irrigation method used (surface canal vs. sprinklers), $77.4 \%$ of farmers who used ISI have efficiency levels greater than 70 percent, which is much higher than that of those who had used FI and TSI ( $8 \%$ and $52.6 \%$ respectively) - a clear indication that using ISI helps in the improvement of productive efficiency.

The stochastic dominance criterion also showed that the shift from TSI to ISI led to $10 \%$ and $13 \%$ reduction in risk of obtaining yield levels below 4 tons/ha and 3 tons/ha respectively. These results all together indicate that investment in improved supplemental irrigation (ISI) helps in the reduction of risk in wheat production. The use of sprinklers, improved wheat varieties particularly those which are drought tolerant, and the use of nitrogen fertilizers along with ISI played an important role in enhancing productive efficiency and hence productivity as well as in reducing income risks for wheat farmers in Syria.

ISI has the potential for enhancing food security and environmental sustainability in the Syria and other countries with dry land agriculture under similar production conditions. An important policy implication of these findings is that wider dissemination of ISI along with other complementary agronomic practices in postwar Syria could be a viable option to be considered by national and international efforts for the restoration and rehabilitation of agriculture in the country.

\section{Acknowledgements}

This study was carried out as a partial fulfillment for a $\mathrm{PhD}$ study at Damascus University, Syria. The authors thank the International Center for Agricultural Research in the Dry Areas (ICARDA) and CRP-Wheat for the financial support which made the study and publication of this manuscript possible.

\section{References}

[1] Grillo, G. and Pandey, S. (1989) Irrigation and Crop Yield Variability: A Review. In: Anderson, J.R. and Hazell, P.B.R., Eds., Variability in Grain Yield: Implications for Agricultural Research and Policy in Developing Countries, The Johns Hopkins University Press, Baltimore, MD. 
[2] Wheeler, T. and von Braun, J. (2013) Climate Change Impacts on Global Food Security. Science, 341, 508-513. https://doi.org/10.1126/science.1239402

[3] Asseng, S., Ewert, F., Rosenzweig, C., Jones, J., Hatfield, J., Ruane, A., Boote, K., Thorburn, P., Rotter, R. and Cammarano (2013) Uncertainty in Simulating Wheat Yields under Climate Change. NAT CLIM CHANGE, 3, 827-832.

[4] Hardaker, J.B., Huirne, R.B.M. and Anderson, J.R. (1997) Coping with Risk in Agriculture. CAB International, Oxon, UK.

[5] Just, R.E. and Pope, R.D. (1978) Stochastic Specification of Production Functions and Economic Implications. Journal of Econometrics, 7, 67-86.

https://doi.org/10.1016/0304-4076(78)90006-4

[6] Pope, R.D. and Kramer, R.A. (1979) Production Uncertainty and Factor Demands for the Competitive Firm. Southern Economic Journal, 46, 489-501. https://doi.org/10.2307/1057421

[7] Antle, J.M. (1983) Incorporating Risk in Production Analysis. American Journal of Agricultural Economics, 65, 1099-1106. https://doi.org/10.2307/1240428

[8] Binswanger, H.P. (1980) Attitudes towards Risk: Experimental Measurement in Rural India. American Journal of Agricultural Economics, 62, 395-407. https://doi.org/10.2307/1240194

[9] Walker, T.S. and Ryan, J.G. (1990) Village and Household Economies in India's Semi-Arid Tropics. Johns Hopkins University Press, Baltimore.

[10] Pandey, S. (2000) Risk and Rainfed Rice: Some Conceptual and Methodological Issues. In: Pandey, S., Barah, B.C., Villano, R.A. and Pal, S., Eds., Risk Analysis and Management in Rainfed Rice Systems, Limited Proceedings No. 5, International Rice Research Institute.

[11] Oweis, T. (1997) Supplemental Irrigation: A Highly Efficient Water Use Practice. ICARDA, Aleppo.

[12] Shideed, K., Oweis, T., Gabir, M. and Osman, M. (2005) Assessing Water Use Efficiency: A New Approach. Vol. 14, ICARDA, Aleppo, 86 p.

[13] Salkini, A.B. (1992) Impact Assessment of Supplemental Irrigation on Rain-Fed Wheat-Based Farming Systems in Syria. PhD Thesis, University of Reading, UK.

[14] Yigezu, Y.A., Aw-Hassan, A., Shideed, K. and El-Shatter, T. (2014) A Policy Option for Valuing Irrigation Water in the Dry Areas. Water Policy Journal, 16, 520-535. https://doi.org/10.2166/wp.2014.141

[15] CBS-Syrian Arab Republic Central Bureau of Statistics. (2005) Annual Statistical Abstracts for 2005CBS-Syrian Arab Republic Central Bureau of Statistics. Annual Statistical Abstracts for 2005.

[16] FRMP Farm Resource Management Program (1995) Annual Report for 1994. International Center for Agricultural Research and the Dry Areas (ICARDA), Aleppo.

[17] Munla Hasan. (2007) Water Use Efficiency in Syrian. Agriculture, National Agricultural Policy Center, Working Paper No 26.

[18] ACSAD and BGR (2002) The Arab Center for the Studies of Arid Zones and Dry Lands and the German Federal Institute for Geosciences and Natural Resources. Groundwater Vulnerability and Hazards to Groundwater in the Damascus Ghoutaplain in Syria.

https://www.whymap.org/EN/Themen/Wasser/Projekte/abgeschlossen/TZ/Acsad/ Vol_4_fb_pdf.pdf?_blob=publicationFile\&v=3

[19] MAAR Ministry of Agriculture and Agrarian Reforms, Syrian Arab Republic (2011) Annual Agricultural Statistics, 2011. MAAR. 
[20] WB The World Bank (2001) Irrigation Sector Report on Syrian Arab Republic. Rural Development, Water, and Environment Group, Middle East and North Africa Region, The World Bank, Report No. 22602-SYR.

[21] Rabboh, R. (2007) Water Demand Management in Syria. 3rd Regional Workshop on Water and Sustainable Development in the Mediterranean: Water Demand Management in the Mediterranean, Progress and Policies, Zaragoza, 17-21 March 2007.

[22] Shomo, F., Ahmed, M., Shideed, K., Aw-Hassan, A. and Erkan, O. (2010) Sources of Technical Efficiency of Sheep Production Systems in Dry Areas in Syria. Small Ruminant Research, 9, 160-169. https://doi.org/10.1016/j.smallrumres.2010.03.009

[23] Zhang, T. and Xue, B. (2005) Environmental Efficiency Analysis of China's Vegetable Production. Biomedical and Environmental Sciences, 18, 21-30.

[24] Kebede, T.A. (2001) Farm Household Technical Efficiency: A Stochastic Frontier Analysis: A Study of Rice Producers in Mardi Watershed in the Western Development Region of Nepal. MSc Thesis, Department of Economics and Social Sciences, Agricultural University of Norway, Norway.

[25] Battese, G.E. and Coelli, T.J. (1995) A Model for Technical Inefficiency Effects in a Stochastic Frontier Production Function for Panel Data. Empirical Economics, 20, 325-332. https://doi.org/10.1007/BF01205442

[26] Karagiannis, G., Tzouvelekas, V. and Xepapadeas, A. (2003) Measuring Irrigation Water Efficiency with a Stochastic Production Frontier: An Application to Greek Out-of-Season Vegetable Cultivation. Environmental and Resource Economics, 26, 57-72. https://doi.org/10.1023/A:1025625402762

[27] Dhehibi, B., Lachaal, L., Elloumi, M. and Messaoud, E.B. (2007) Measuring Irrigation Water Use Efficiency using Stochastic Production Frontier: An Application on Citrus Producing Farms in Tunisia. African Journal of Agriculture and Resource Economics, 2, 1-15.

[28] Just, R.E. and Pope, R.D. (1979) Production Function Estimation and Related Risk Considerations. American Journal of Agricultural Economics, 61, 276-284. https://doi.org/10.2307/1239732

[29] Battese, G.E., Rambaldi, A.N. and Wan, G.H. (1997) A Stochastic Frontier Production Function with Flexible Risk Properties. Journal of Productivity Analysis, 8, 269-280. https://doi.org/10.1023/A:1007755604744

[30] Wang, H.J. (2002) Heteroscedasticity and Non-Monotonic Efficiency Effects of a Stochastic Frontier Model. Journal of Productivity Analysis, 18, 241-253. https://doi.org/10.1023/A:1020638827640

[31] Aigner, D., Lovell, C. and Schmidt, P. (1977) Formulation and Estimation of Stochastic Production Models. Journal of Econometrics, 6, 21-37. https://doi.org/10.1016/0304-4076(77)90052-5 